\title{
A coprological survey of parasitic fauna firstly in Wild Far Eastern Leopard (Panthera pardus orientalis)
}

zhijun hou ( $\nabla$ houzhijundz@163.com )

Central South University of Forestry and Technology https://orcid.org/0000-0002-7239-3347

\section{Zhiwei Peng}

Northeast Forestry University

\section{Yao Ning}

Northeast Forestry University

Guangshun Jiang

Northeast Forestry University

Research article

Keywords: Amur leopard; Panthera pardus orientalis; parasitic fauna

Posted Date: July 23rd, 2019

DOI: https://doi.org/10.21203/rs.2.11851/v1

License: (c) (i) This work is licensed under a Creative Commons Attribution 4.0 International License.

Read Full License 


\section{Abstract}

Background $\triangle T$ The Amur leopard, one of nine recently recognized subspecies of leopard, is still most threatened in a stochastic procession of extinction. The potential harmless to the conservation of the Amur leopard originating from the disease is in need of urgent attention. Unfortunately, the research on the potential risk to Amur leopard caused by disease is rare. When the parasites were concerned, even the elementary data, such as parasitic fauna, are absent. Our aim in the study is to accumulate the knowledge of it for a better comprehension. Results: There are 7 parasite species, including 3 nematodes (Toxocara cati, capillarid-type parasite, and Metastrongyloidea-type parasite), 2 cestodes (Spirometra sp. and Taenia sp.), 1 trematode (Paragonimus sp.), and 1 protozoa (Cystoisospora felis), were found in this research. The Toxocara cati was highest frequent occurrence, followed by Spirometra sp. Conclusion: The Amur leopard was infected by seven parasites firstly reported.

\section{Background}

The leopard (Panthera pardus) is a solitary, reclusive species of big feline. It is also the most widespread felid, extending across much of Africa, and Asia from the Middle East to the Pacific Ocean, acting substantial functions for the ecosystems [1]. The Far Eastern leopard (Panthera pardus orientalis), also known as the Amur leopard, is one of nine recently recognized subspecies of leopard, whose population and geographic range drastic declining and has lost as much as $98 \%$ of their historic range due to the habitat modification, prey depletion, and poaching [2] [3]. Until the two subpopulation of Amur leopard in northern of Primorski Krai disappeared by 1985, the one of the present study becomes only single subpopulation in the planet (Pikunov and Korkishko, 1985) [3]. The subpopulation reside in the region occupying approximately $7,000 \mathrm{~km}^{2}$, it is around the borders of the Northeast of China, the extreme southwest of the Primorskii krai (the Far East of Russian), and the extreme north of North Korea [2] [3] [4]. Although the numbers of it is increases in recently [1], however, the Amur leopards on the whole are as few as about 60 individuals[2].As the Amur leopard still is most threatened in a stochastic procession of extinction[5], it is currently classified as Critically Endangered by the International Union for Conservation of Nature, listed in Appendix I of the Convention on International Trade of Endangered Species of Wild Fauna and Flora [2] [1].

Along with the attention paid on the Amur leopard increasing, a few researches are taken on the ecology with population, potential supporting prey, habitat situation, distribution, and genetic diversity[6] [1] [7] [4], however, little research on the disease is made. As the diseases have lethality adverse to protection of the wild Amur tiger [8], it reminds us that the situation of Amur leopard is likely with Amur tiger or even worse because it is a small, single population. Therefore, the potential harmless to the conservation of the Amur leopard originating from the disease is in need of urgent attention. Unfortunately, the research on the potential risk to Amur leopard caused by disease is rare. When the parasites were concerned, even the elementary data, such as parasitic fauna, are absent. Our aim in the study is to accumulate the knowledge of it for a better comprehension. 


\section{Results}

There are 7 parasite species, including 3 nematodes, 2 cestodes, 1 trematode, and 1 protozoa, were found in this research (see Table 1, Fig. 1). The appearing frequency, infect intensities, and parasite egg sizes were show in the Table 1. The morphology characteristic of parasite eggs was show in Fig. 2. The Toxocara cati was higher prevalence, followed by Spirometra sp.

\section{Discussion}

The Toxocara cati is a worldwide parasite of felids, and it is very popular in the both captured and wild Siberian tigers [9-11]. Our research indicates that the Toxocara catialso is a common parasite in wild Amur leopard with a high frequency of $61.9 \%$. In general, the Amur tiger, nearly completely sympatric with Amur leopard, could infect two kinds of roundworm, Toxocara cati and Toxascaris leonine. For the captured tiger, both of them are very popular, whereas Toxascaris leonine is rare in the wild Amur tigers [911]. The situation of Amur leopard is little difference in Amur leopard as there no Toxascaris leonine was found in the wild population in current study.

The capillarid type parasites are wildly distributed in the domestic and wild carnivores, and there are four speicies, including Eucoleus aerophilus (syn. Capillaria aerophila), Aonchotheca putorii (syn. Capillaria putorii), Eucoleus boehmi, and Calodium hepaticum (syn. Calpillaria hepatica, Hepaticola hepatica), have been recorded in felines [12] [13] [14] [15] [16]. The capillarid type parasites in this research were identified as Eucoleus aerophilus or Aonchotheca putorii by the characteristics of eggs [14] [17]. Eucoleus aerophilus is a globally distributed parasite among various wild carnivorous mammals, and resides embedded in host's epithelium of the trachea, bronchi and bronchioles of the lungs. Usually, the pathogenicity of it is considered subclinical with respiratory distress coughing and wheezing, may be the clinical presentations in heavily infected hosts [15]. Aonchotheca putorii is a parasitic nematode of the stomach and small intestines of many wild mammals, and causes severe gastric, associated with a gastric ulcer and secondary anemia [16]. What special species the parasite is need a molecular identification in future.

Troglostrongylus brevior (Metastrongyloidea, Crenosomatidae) and Aelurostrongilus abstrusus (Metastrongyloidea, Angiostrongylidae) are two important feline lungworms [18] [19]. The A. abstrusus is a common nematode of domestic cats, with a widespread and worldwide distribution [18] [20]. While $T$. brevior have been regarded as infected the wild feline only and been neglected for a long time until some domestic cat infestation cases were reported in recently [19] [21] [22], and it was always thought distributed limited around Mediterranean Europe [23]. The adult worms of $A$. abstrusus is localized in the alveolar ducts and the bronchioles and it can cause respiratory signs like cough, dyspnea, pulmonary wheezes, chronic wasting, and a considerable impact on the healthy and welfare [18]. T. brevior also localizes in the host's respiratory system, and can cause cough, dsypnea, severe respiratory distress, and a fatal outcome in kitten [19] [21]. The wild felids have been thought was more susceptible host for $T$. brevior than domestic cat, and it occurrences in domestic cats is regarded as atypical, yet it needs more 
reliable evidence to confirm [19]. In current study, the larvae was recognized as T. brevior based on the larvae morphology such as the tail characteristic and body size, and the epidemiological endemic, such as $T$. brevior was always present in the wild feline, the wildcats may be the natural hosts of $T$. brevior. However, $A$. abstrusus could not be excluded as they overlap the features of L1 (the first stage of larvae, the diagnostic stage of $A$. abstrusus and T. brevior) [21] [22] [23] [19].

The Spirometra spp., a Pseudophyllidae tapeworm, occupies the intestine of feline and canine definitive hos. The first intermediate host for the parasite is copepod and the second one always are amphibians, reptiles like frogs (tadpole) and snakes [24] [25]. The domestic cat and dog are frequent with high Spirometra spp. infestation [25], while wild carnivores were ones sporadically [26] [27]. As far as the wild felines were concerned, the Panthera leo [28], Lynx lynx [24], leopardus pardalis[26], Lynx rufus, Oncifelis guigna, Puma concolor, Panthera onca, [27] and Panthera tigris [11] have been found positive with Spirometra spp. Some wild carnivores also could be as the paratenic hosts with the stage of spargana, such as Meles meles, Erinaceus europeaus, Martes foina, Mustela putorius, Mus decumanus, Mustela Iutreola, Neovison vison, Lutra Iutra, Nyctereutes procyonoides, Mustela ermine, Mustela nivalis, and Sorex araneus [29], and most of them were the prey of the leopard. Therefore, it is not strange that the parasite also could found in the Amur leopard with a high frequency of Spirometra spp. (38.1\%).

Taenie spp., cosmopolitan parasitic tapeworms in animal medicine, including about 45 species, lives on the small intestine of carnivorous mammals, where they complete development to adults and reproduce [30]. Given the Taenie species of feline host, fourteen could take feline as the final host, such as Taenia laticollis, T. omissa, T. taeniaeformis (Syn. H. taeniaeformis) [30] (Loos-Frank, 2000). The herbivorous and omnivorous always are the intermediate hosts, in which the metacestode inhabits and develops to the stage could infect the final host. A predator-prey relationship between the definitive and intermediate hosts maintains the transmission of Taenia spp. The felids, including Lynx lynx, Lynx rufus, Lynx Canadensis, Puma concolor, Felis margarita, Panthera leo, Panthera tigris, and Felis catus have been found Taenie spp. could occurred in them [30] [31] [32] [33] [11] [34] . Amur leopard, a big size cat, Holarctic felid, preys on a wide range of mammals, but it's overwhelming majority of diets were roe deer (up to $66 \%$ ), wild boars (up to $8 \%$ ), Siberian musk deer (up to $9 \%$ ), and sika deer (up to 6\%)[7]. Therefore, Amur leopard was involved in the life cycles of Taenia sp is not out anticipation. Although it could be concluded that Taenia worms infected the Amur leopard based on presenting the distinctly Taenia eggs, developed larva with 3 pairs of hooks, and surrounded by a thick and striated shell, however, it is difficult to discriminate the Taenia species only based on the morphological characteristics of the eggs as all species of Taenia genus share those special characteristics.

The Paragonimus spp., lung flukes, are trematodes that parasitize the lungs of mammal animals like Carnivores, the major definitive host. The first intermediate hosts are snails, in which the myracidium lives, and the second intermediate hosts are crustaceans, crabs or crayfishes, where the metacercariae resides. The definitive hosts become infected by eating raw or under-cooked second intermediate hosts or by eating under-cooked meat of paratenic hosts, such as wild boar and sika deer, which contains juvenile 
worms[35] [36] [37]. The latter route seems to be more important in Amur leopard, as it always take the wild boar, sika deer and roe deer as food other than crustaceans [7].

There are about fifty nominal Paragonimus species, meanwhile, over half of them have been found in China, one of the major endemic foci of paragonimiasis in the world. Two of them, $P$. westermani and $P$. skrjabini, known zoonotic parasites, are more commonly or focused in China. Although most of Paragonimus spp. occur in tropical and subtropical regions, however, two species, $P$. westermani and $P$. ohirai, extend far into temperate latitudes of China [35]. The $P$. westermani, the only one, converges the habitats of the Amur leopards. Although twenty of them were found within the cat, while only seven of them, including $P$. westermani, were found in wild felines [35]. For $P$. westermani, it was initially recognized from a Bengal Tiger at the Amsterdam zoological gardens, which migrated from Asia. Thereafter, other seven feline hosts, including felis catus, Catopuma temminckii, Neofelis nebulosa, Panthera pardus, Prionailurus bengalensis, Prionailurus planiceps, and Prionailurus rubiginosus, found could be infected by $P$. westermani [35]. The trematode of Amur leopard was easily identified as paragonimus with the features of the eggs, the distantly shoulders or opercular ridges which are useful for differentiating Paragonimus eggs from the large operculate eggs of other trematodes [38]. For the specific Paragonimus species discrimination, with a high degree certainty, it was the $P$. westermani based on the epidemiological data, such as the parasite's endemic region and host species recorded in the past. However, it is not sufficient to deny the possibility of the other Paragonimus spp. without molecular evidence.

There are only two coccidian species, Cystoisospora felis (syn. Isopora felis) and C. rivolta (syn. Isopora rivolta), in cats. The typical symptom of Cystoisospora was diarrhea in kittens, occasionall mortality for C. Felis [39]. The egg size of $C$. felis $(32-53 \times 26-43 \mu \mathrm{m})$ is much bigger than $C$. rivolta $(18-25 \times 16-23$ $\mu \mathrm{m})$ [39], so it was certainly identified that the coccidian species from Amur leopard as the $C$. felis based on the eggs sizes. Until now, with the Amur leopard together, those wild felines, including Panthera tigris, Panthera leo, Panthera pardus, Lynx rufus, and Felis silvestris, have been found infected C. felis [39] [40] [41] [42] [43] [44]. Traditionally, the $C$. felis was thought transmitted by oral uptake of oocysts without intermediate host, but this was obviously impracticable for wild Amur leopard as their population density are much lower that domestic felines. Therefore, paratenic host must play an important role in transmission of $C$. felis. Actually, based on the results of bioassay studies, the animals like dog, cattle, pig, mice, and rabbit may act as paratenic host for Cystoisospora has been discussed in the past[39].

The wild Amur leopards, a solitary, reclusive species, its life history, living environment, and food have a big difference with the domestic cat. So, the parasite of it, especial the nematodes without intermediate host, must have optional ways instead of the traditional oral-feces route. Considered the paratenic host, which always in the food-chain of the big carnivore, is a necessary actor in parasite distribution among wild Amur leopard will not be too seriously. With the instance of the parasites without intermediate host in the present study, Toxocara cati, capillarid-type , Metastrongyloidea-type, and Cystoisospora felis, all of them are suspected taking paratenic host for their transmission [45]. 
The non-invasive sampling approach, based on collection of scats in the environment, is extraordinary favorable for epidemiological studies on wild carnivore animals, and necessary when protected species are investigated without interfering in the existing structure of the population. However, the study based on mostly scats collected in the environment did not allow the individual animal identification and some stool samples belonged to the same animal cannot be exclude. Therefore, the term frequency was used instead of prevalence to describe the proportion of parasite infections in this research [46].

\section{Conclusion}

The Amur leopard were infected by seven parasites firstly reported.

\section{Methods}

The research was carried in the Northeast of China, and most samples were collected in the Wangqing National Nature Reserve (Fig.2). After permission was granted by local government, 42 fecal samples were collected opportunistically from the ground in the areas where Amur leopards resided from 20132015. The samples were collected in winter to early spring, in that time the local temperature is absolutely below $0{ }^{\circ} \mathrm{C}$. The samples were stored in $-80^{\circ} \mathrm{C}$ frozen after back to the laboratory. Parasitic eggs were separate with saturated solution of sodium chloride as the floating medium and identified based on the morphological characteristics with the microscope mechanic, infection intensity was determined by the modified McMaster technique, the detective limitation is $60 \mathrm{n} / \mathrm{g}$ [47].

\section{Declaration}

\section{Abbreviations}

Not applicable

\section{Ethics approval and consent to participate}

Collecting the feces samples from the wild Amur leopard was approved by the local government agents.

\section{Consent for publication}

Not applicable

\section{Availability of data and materials}

All the data and materials used in this report are included in the manuscript.

\section{Competing interests}

The authors declare that they have no competing interests. 


\section{Funding}

This study was supported by the following Grants: National Key Research and Development Program (project 2017YFD0501702), Fundamental Research Funds for the Central Universities (2572018BE07) and Surveillance of Wildlife Diseases from the State Forestry Administration of China. The funding body was solely involved in funding and had no role in the design of the study, the collection, analysis, and interpretation of the data, or in writing the manuscript.

\section{Authors' contributions}

ZH designed the research and wrote the manuscript. ZP and YN collected the samples and isolated parasite eggs of the Amur Leopard. GJ helped in conceived of this work and participated in its design. All authors read and approved the final manuscript.

\section{Acknowledgments}

We thank Prof. Douglas Bowman Dwight and Dr. Araceli Lucio-Forste of Cornell University for their assistance in parasite identification and some valuable scientific suggestions on this manuscript.

\section{References}

1. Jacobson AP, Gerngross P, Lemeris JR, Jr., Schoonover RF, Anco C, Breitenmoser-Wursten C, Durant SM, Farhadinia MS, Henschel P, Kamler JF et al: Leopard (Panthera pardus) status, distribution, and the research efforts across its range. PeerJ 2016, 4:e1974.

2. Sulikhan NS, Gilbert M, Blidchenko EY, Naidenko SV, Ivanchuk GV, Gorpenchenko TY, Alshinetskiy MV, Shevtsova El, Goodrich JM, Lewis JCM et al: Canine Distemper Virus in a Wild Far Eastern Leopard ( Panthera Pardus Orientalis). Journal of wildlife diseases 2018, 54(1):170-174.

3. Mark Hebblewhite, Dale G. Miquelle, Andre A. Murzin, Vladimir V. Aramilev, Pikunov DG: Predicting potential habitat and population size for reintroduction of the Far Eastern leopards in the Russian Far East. corsevation biology 2011, 144: 2403-2413.

4. Rozhnov VV, Sorokin PA, Lukarevskii VS, Naidenko SV, Ernandes-Blanko Kh A, Lukarevskii SV: Individual identification of Amur leopards (Panthera pardus orientalis) using molecular-genetic methods and estimation of the population]. Izvestiia Akademii nauk Seriia biologicheskaia 2013(2):138-143.

5. Kelly P, Stack D, Harley J: A review of the proposed reintroduction program for the Far Eastern leopard (Panthera pardus orientalis) and the role of conservation organizations, veterinarians, and zoos. Topics in companion animal medicine 2013, 28(4):163-166.

6. Vitkalova AV, El. S: A complex approach to study the Amur leopard using camera traps in protected areas in the southwest of Primorsky Krai (Russian Far East) Nature Conservation Research 2016, 1(3):53-58. 
7. Jiang G, Qi J, Wang G, Shi Q, Darman Y, Hebblewhite M, Miquelle DG, Li Z, Zhang X, Gu J et al: New hope for the survival of the Amur leopard in China. Scientific reports 2015, 5:15475.

8. Gilbert M, Soutyrina SV, Seryodkin IV, Sulikhan N, Uphyrkina OV, Goncharuk M, Matthews L, Cleaveland S, Miquelle DG: Canine distemper virus as a threat to wild tigers in Russia and across their range. Integrative zoology 2015, 10(4):329-343.

9. Peng Z, Liu S, Hou Z, Xing M: Ascarid infestation in captive Siberian tigers in China. Veterinary parasitology 2016, 226:74-77.

10. Gonzalez P, Carbonell E, Urios V, Rozhnov VV: Coprology of Panthera tigris altaica and Felis bengalensis euptilurus from the Russian Far East. The Journal of parasitology 2007, 93(4):948-950.

11. Moskvina TV, Schelkanov MY, Begun MA: Endoparasites of the Siberian tiger (Panthera tigris altaica). Integrative zoology 2018, 13(5):507-516.

12. Borba VH, Machado-Silva JR, Le Bailly M, Iniguez AM: Worldwide paleodistribution of capillariid parasites: Paleoparasitology, current status of phylogeny and taxonomic perspectives. PloS one 2019, 14(4):e0216150.

13. Karawita AC, Perera VP, Perera S, de Silva DS, Jayaweera WR, Himsworth CG, Bollinger TK, de SGP: Calodium hepaticum in Jungle Cats (Felis chaus ) in Sri Lanka. Journal of wildlife diseases 2016, 52(4):971-972.

14. Takeuchi-Storm N, Mejer H, Al-Sabi MN, Olsen CS, Thamsborg SM, Enemark HL: Gastrointestinal parasites of cats in Denmark assessed by necropsy and concentration McMaster technique. Veterinary parasitology 2015, 214(3-4):327-332.

15. Knaus M, Shukullari E, Rapti D, Rehbein S: Efficacy of Broadline against Capillaria aerophila lungworm infection in cats. Parasitology research 2015, 114(5):1971-1975.

16. Curtsinger DK, Carpenter JL, Turner JL: Gastritis caused by Aonchotheca putorii in a domestic cat. Journal of the American Veterinary Medical Association 1993, 203(8):1153-1154.

17. Quadros RM, Weiss PH, Miletti LC, Moura AB: OCCURRENCE OF Calodium hepaticum (BANCROFT, 1893) MORAVEC, 1982 EGGS IN FECES OF DOGS AND CATS IN LAGES, SANTA CATARINA, BRAZIL. Revista do Instituto de Medicina Tropical de Sao Paulo 2016, 58:6.

18. Moskvina TV: Current knowledge about Aelurostrongylus abstrusus biology and diagnostic. Annals of parasitology 2018, 64(1):3-11.

19. Brianti E, Giannetto S, Dantas-Torres F, Otranto D: Lungworms of the genus Troglostrongylus (Strongylida: Crenosomatidae): neglected parasites for domestic cats. Veterinary parasitology 2014, 202(3-4):104-112.

20. Elsheikha HM, Schnyder M, Traversa D, Di Cesare A, Wright I, Lacher DW: Updates on feline aelurostrongylosis and research priorities for the next decade. Parasites \& vectors 2016, 9(1):389.

21. Traversa D, Lepri E, Veronesi F, Paoletti B, Simonato G, Diaferia M, Di Cesare A: Metastrongyloid infection by Aelurostrongylus abstrusus, Troglostrongylus brevior and Angiostrongylus chabaudi in a domestic cat. International journal for parasitology 2015, 45(11):685-690. 
22. Diakou A, Di Cesare A, Barros LA, Morelli S, Halos L, Beugnet F, Traversa D: Occurrence of Aelurostrongylus abstrusus and Troglostrongylus brevior in domestic cats in Greece. Parasites \& vectors $2015, \mathbf{8}: 590$.

23. Alic A, Traversa D, Duscher GG, Kadric M, Di Cesare A, Hodzic A: Troglostrongylus brevior in an Eurasian lynx (Lynx lynx) from Bosnia and Herzegovina. Parasites \& vectors 2015, 8:653.

24. Kondzior E, Tokarska M, Kowalczyk R, Ruczynska I, Sobocinski W, Kolodziej-Sobocinska M: The first case of genetically confirmed sparganosis (Spirometra erinaceieuropaei) in European reptiles. Parasitology research 2018, 117(11):3659-3662.

25. Hong Q, Feng JP, Liu HJ, Li XM, Gong LR, Yang Z, Yang WM, Liang XF, Zheng RJ, Cui ZC et al: Prevalence of Spirometra mansoni in dogs, cats, and frogs and its medical relevance in Guangzhou, China. Int J Infect Dis 2016, 53:41-45.

26. Almeida GG, Coscarelli D, Melo MN, Melo AL, Pinto HA: Molecular identification of Spirometra spp. (Cestoda: Diphyllobothriidae) in some wild animals from Brazil. Parasitol Int 2016, 65(5):428-431.

27. Scioscia NP, Petrigh RS, Beldomenico PM, Denegri GM: The Pampas fox (Lycalopex gymnocercus) as new definitive host for Spirometra erinacei (Cestoda: Diphyllobothriidae). Acta tropica 2014, 133:78-82.

28. Eom KS, Park H, Lee D, Choe S, Kang Y, Bia MM, Lee SH, Keyyu J, Fyumagwa R, Jeon HK: Molecular and Morphologic Identification of Spirometra ranarum Found in the Stool of African Lion, Panthera leo in the Serengeti Plain of Tanzania. Korean Journal of Parasitology 2018, 56(4):379-383.

29. Kolodziej-Sobocinska M, Tokarska M, Kowalczyk R: The first report of sparganosis (Spirometra sp.) in Eurasian badger (Meles meles). Parasitol Int 2014, 63(2):397-399.

30. Gomez-Puerta LA, Alarcon V, Pacheco J, Franco F, Lopez-Urbina MT, Gonzalez AE: Molecular and morphological evidence of Taenia omissa in pumas (Puma concolor) in the Peruvian Highlands. Revista brasileira de parasitologia veterinaria = Brazilian journal of veterinary parasitology : Orgao Oficial do Colegio Brasileiro de Parasitologia Veterinaria 2016, 25(3):368-373.

31. Lavikainen A, Haukisalmi V, Deksne G, Holmala K, Lejeune M, Isomursu M, Jokelainen P, Nareaho A, Laakkonen J, Hoberg EP et al: Molecular identification of Taenia spp. in the Eurasian lynx (Lynx lynx) from Finland. Parasitology 2013, 140(5):653-662.

32. Miquel J, Foronda P, Torres J, Swiderski Z, Feliu C: Ultrastructural study of the spermatozoon of Taenia taeniaeformis (Batsch, 1786) (Cestoda, Cyclophyllidea, Taeniidae), an intestinal parasite of Felis catus from La Palma (Canary Islands, Spain). Parasitology research 2009, 104(6):1477-1483.

33. Foster GW, Cunningham MW, Kinsella JM, McLaughlin G, Forrester DJ: Gastrointestinal helminths of free-ranging Florida panthers (Puma concolor coryi) and the efficacy of the current anthelmintic treatment protocol. Journal of wildlife diseases 2006, 42(2):402-406.

34. Loos-Frank B: An up-date of Verster's (1969) 'Taxonomic revision of the genus Taenia Linnaeus' (Cestoda) in table format. Systematic parasitology 2000, 45(3):155-183.

35. Blair D, Xu ZB, Agatsuma T: Paragonimiasis and the genus Paragonimus. Advances in parasitology 1999, 42:113-222. 
36. Sugiyama H, Shibata K, Kawakami Y, Arakawa K, Morishima Y, Yamasaki H, Gokuden M, Iwakiri T, Fukumori J: Paragonimiasis Due to the Consumption of Wild Boar Meat in Japan: Contamination Levels of Lung Fluke Larvae in Muscle Samples of Wild Boars Caught in Kagoshima Prefecture. Jpn $J$ Infect Dis 2015, 68(6):536-537.

37. Yoshida A, Matsuo K, Moribe J, Tanaka R, Kikuchi T, Nagayasu E, Misawa N, Maruyama H: Venison, another source of Paragonimus westermani infection. Parasitol Int 2016, 65(6 Pt A):607-612.

38. Procop GW: North American paragonimiasis (Caused by Paragonimus kellicotti) in the context of global paragonimiasis. Clinical microbiology reviews 2009, 22(3):415-446.

39. Dubey JP: A review of Cystoisospora felis and C. rivolta-induced coccidiosis in cats. Veterinary parasitology 2018, 263:34-48.

40. Hou ZJ, Xing MW, Chai HL, Hua YP: Phylogenetic Position Analysis of an Isospora Isolated From Siberian Tiger in Eimeriid Coccidian Based on 18S rDNA Sequence. Pak J Zool 2011, 43(3):505-510.

41. Napoli E, Anile S, Arrabito C, Scornavacca D, Mazzamuto MV, Gaglio G, Otranto D, Giannetto S, Brianti E: Survey on parasitic infections in wildcat (Felis silvestris silvestris Schreber, 1777) by scat collection. Parasitology research 2016, 115(1):255-261.

42. Dubey JP, Houk AE, Verma SK, Calero-Bernal R, Humphreys JG, Lindsay DS: Experimental transmission of Cystoisospora felis-like coccidium from bobcat (Lynx rufus) to the domestic cat (Felis catus). Veterinary parasitology 2015, 211(1-2):35-39.

43. Bjork KE, Averbeck GA, Stromberg BE: Parasites and parasite stages of free-ranging wild lions (Panthera leo) of northern Tanzania. Journal of zoo and wildlife medicine : official publication of the American Association of Zoo Veterinarians 2000, 31(1):56-61.

44. Patton S, Rabinowitz AR: Parasites of wild felidae in Thailand: a coprological survey. Journal of wildlife diseases 1994, 30(3):472-475.

45. Zajac A, Conboy GA: Veterinary clinical parasitology, 8th edn. Chichester, West Sussex, UK: WileyBlackwell; 2012.

46. Gori F, Armua-Fernandez MT, Milanesi P, Serafini M, Magi M, Deplazes P, Macchioni F: The occurrence of taeniids of wolves in Liguria (northern Italy). International journal for parasitology Parasites and wildlife 2015, 4(2):252-255.

47. Nwosu CO, Madu PP, Richards WS: Prevalence and seasonal changes in the population of gastrointestinal nematodes of small ruminants in the semi-arid zone of north-eastern Nigeria. Veterinary parasitology 2007, 144(1-2):118-124.

\section{Table}

Table 1 The fauna, eggs size, frequency and intensity of the parasite in Amur leopard 


\begin{tabular}{lllll} 
Parasitic species & $\begin{array}{l}\text { Egg } \\
\text { sizes } \\
\mu \mathrm{m}\end{array}$ & $\begin{array}{l}\text { frequency } \\
\%\end{array}$ & $\begin{array}{l}\text { Infection } \\
\text { intensity } \\
\mathrm{EPG}^{\mathrm{a}}\end{array}$ & $\begin{array}{l}\text { Highest infection } \\
\text { intensity EPG }\end{array}$ \\
\hline $\begin{array}{l}\text { Toxocara cati } \\
\begin{array}{l}\text { Eucoleus aerophilus or } \\
\text { Aonchotheca putorii }\end{array}\end{array}$ & $28 \times 55$ & $26.21 \%$ & 20.33 & 300 \\
\hline $\begin{array}{l}\text { Lungworm } \\
\text { (Metastrongyloidea) }\end{array}$ & $312 \times 17^{\mathrm{b}}$ & $9.5 \%$ & $\backslash$ & 1 \\
\hline $\begin{array}{l}\text { Spirometra sp. } \\
\text { Taenia sp. }\end{array}$ & $42 \times 70$ & $38.10 \%$ & 428.31 & 3510 \\
\hline Paragonimus sp. & $30 \times 32$ & $2.4 \%$ & $\backslash$ & 1 \\
\hline Cystoisospora felis & $54 \times 76$ & $2.4 \%$ & $\backslash$ & 1 \\
\hline
\end{tabular}

Note冈a Eggs Per Gram, EPG; b larva

\section{Figures}



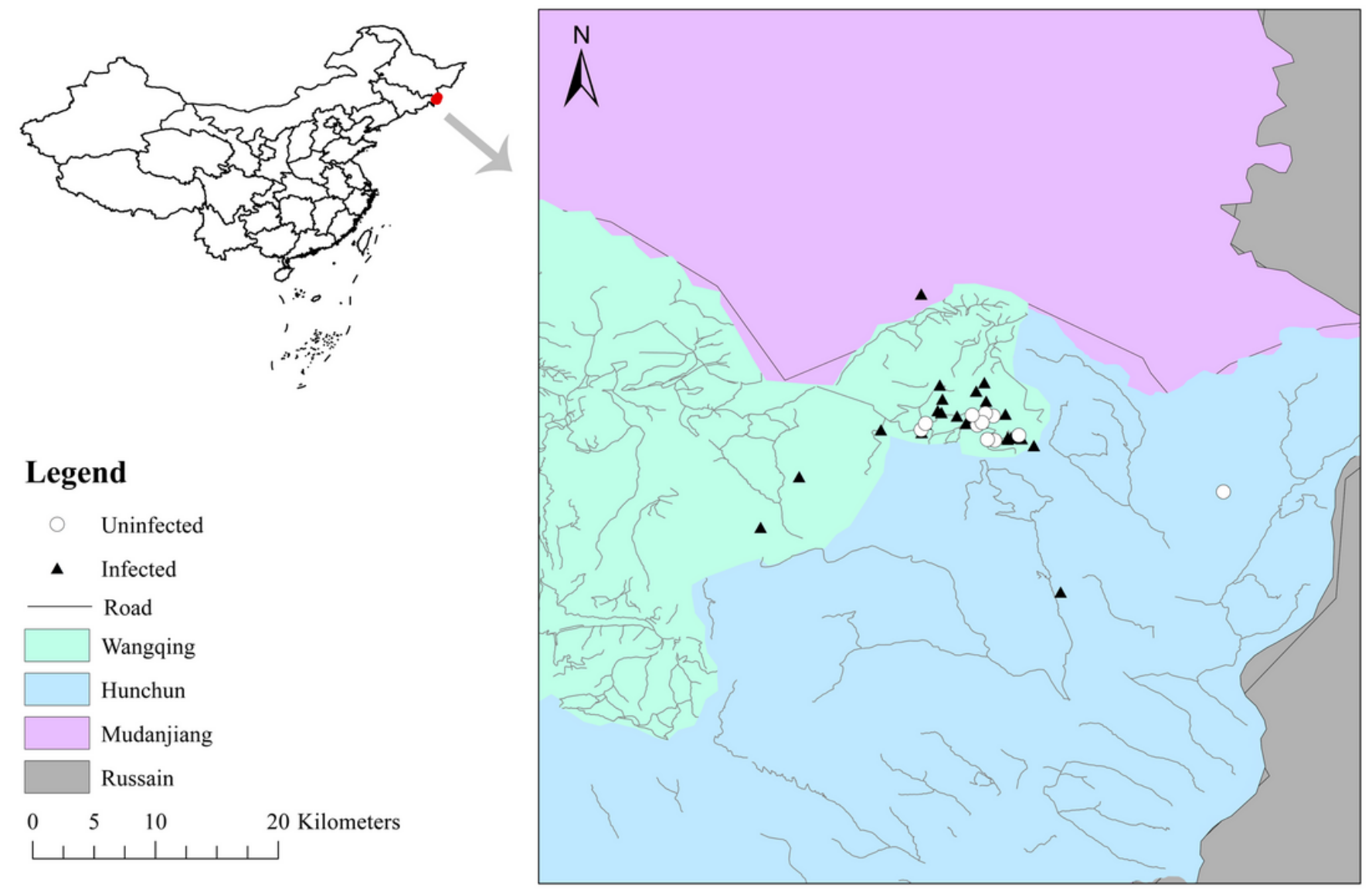

Legend

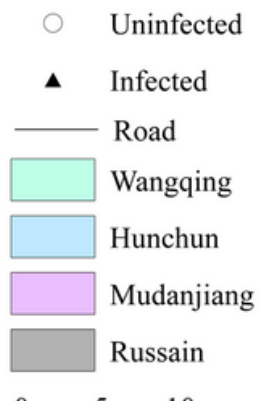

20 Kilometers

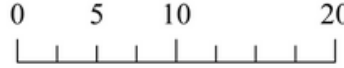

\section{Figure 1}

The eggs morphology features of the parasites among Amur leopards 2-1 Toxocara cati; 2-2 The capillarid type parasite; 2-3 Metastrongyloidea-lungworm; 2-4; Paragonimus sp. 2-5 Spirometra sp.; 2-6 Taenia sp.; 2-7 Cystoisospora felis The picture showed the morphological characteristic of the targeted parasite eggs. 

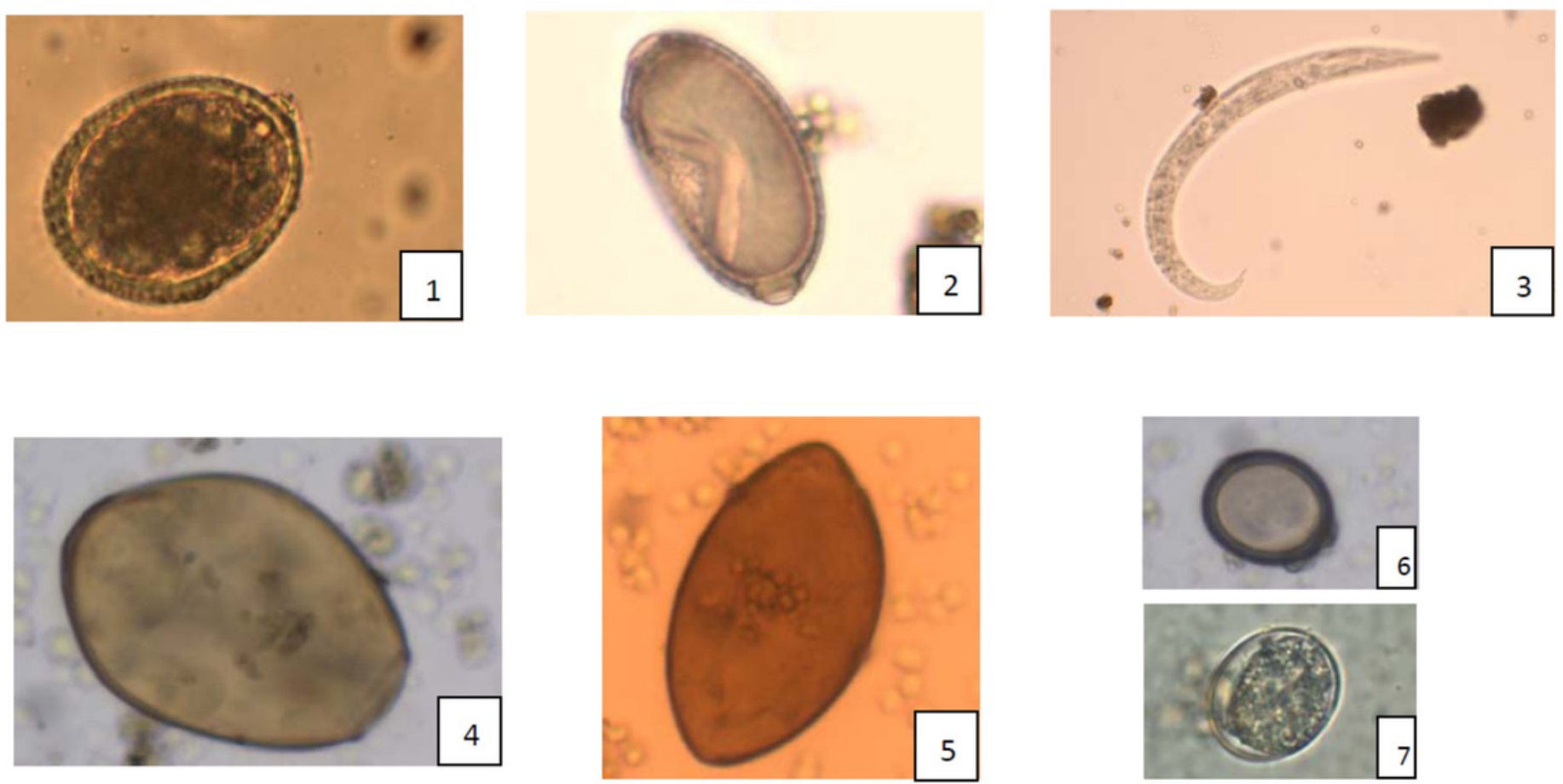

Figure 2

The picture showed the site of the samples were collected, it was made by one author Dr Zhiwei Peng. 